\title{
Titanium-mediated reductive cross-coupling reactions of imines with terminal alkynes: An efficient route for the synthesis of stereodefined allylic amines
}

\author{
Kebin Mao ${ }^{1,2}$, Guoqin Fan¹, Yuanhong Liu ${ }^{*} 1, \S$, Shi Li ${ }^{1}$, Xu You ${ }^{1}$ \\ and Dan Liu²
}

\section{Full Research Paper}

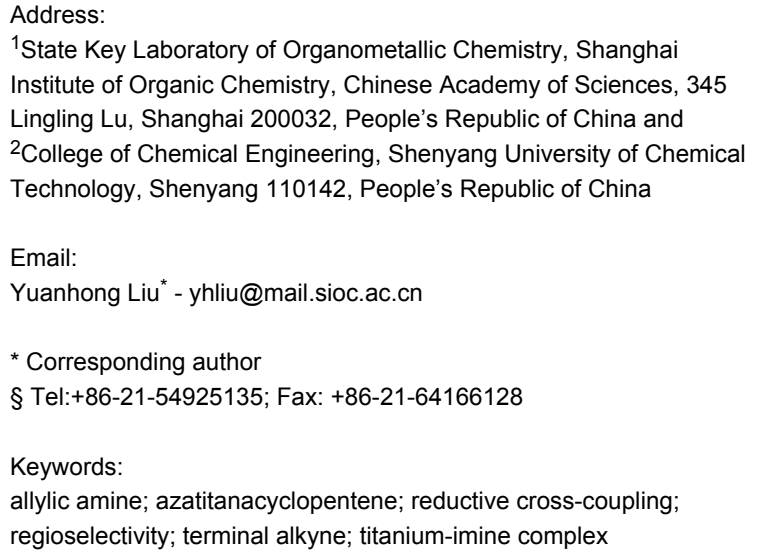

${ }^{1}$ State Key Laboratory of Organometallic Chemistry, Shanghai Institute of Organic Chemistry, Chinese Academy of Sciences, 345 Lingling Lu, Shanghai 200032, People's Republic of China and ${ }^{2}$ College of Chemical Engineering, Shenyang University of Chemical Technology, Shenyang 110142, People's Republic of China

Email:

Yuanhong Liu* - yhliu@mail.sioc.ac.cn

* Corresponding author

§ Tel:+86-21-54925135; Fax: +86-21-64166128

Keywords:

allylic amine; azatitanacyclopentene; reductive cross-coupling;

regioselectivity; terminal alkyne; titanium-imine complex

\author{
Beilstein J. Org. Chem. 2013, 9, 621-627. \\ doi:10.3762/bjoc.9.69 \\ Received: 25 December 2012 \\ Accepted: 04 March 2013 \\ Published: 27 March 2013 \\ Associate Editor: K. Itami \\ (c) 2013 Mao et al; licensee Beilstein-Institut. \\ License and terms: see end of document.
}

\begin{abstract}
Low-valency titanium species, generated in situ by using $\mathrm{Ti}(\mathrm{OiPr})_{4} / 2 c-\mathrm{C}_{5} \mathrm{H}_{9} \mathrm{MgCl}$ reagent, react with imines to give a titaniumimine complex that can couple with terminal alkynes to provide azatitanacyclopentenes with excellent regioselectivity. Stereodefined allylic amines are obtained in good yields after hydrolysis or iodonolysis of the corresponding azatitanacyclopentenes. When ethynylcyclopropane is used as the coupling partner to react with imines in this reaction, the initially generated allylic amine undergoes an unexpected 1,3-amino migration on silica gel during the column chromatography.
\end{abstract}

\section{Introduction}

Allylic amines are fundamental three-carbon building blocks in organic chemistry and their synthesis is an important industrial and synthetic goal [1-4]. The two functionalities in the allylic amine fragment, i.e., the nucleophilic amino group and the alkene, can ideally participate in cycloaddition reactions $[5,6]$, condensation reactions [7], nucleophilic substitution reactions [8,9], radical reactions [10] and Pd-catalyzed reactions [11].
Thus, allylic amines have been used for the synthesis of numerous heterocycles and bioactive amines, such as $\alpha$ - and $\beta$-amino acids [12-15], different alkaloids [16], aminoallylsilanes [17], aminoepoxides [18], iodocyclocarbamates [19] and isoxazolines [20]. Although it has been reported that allylic amines can be synthesized by methods such as amination of allylic alcohols [21-24], direct allylic amination of simple alkenes [25-27], 
Morita-Baylis-Hillman reaction [28], alkenylation of imines [29-32], etc., it is still a great challenge to synthesize allylic amines with a stereodefined alkene moiety. The low-valency group 4 metal complexes $(\mathrm{M}=\mathrm{Ti}$ or $\mathrm{Zr})$ mediated reductive cross-coupling of imines with alkynes is one of the useful methods to construct stereodefined allylic amines. For example, Buchwald et al. reported that zirconocene-imine complexes, generated by treating $\mathrm{Cp}_{2} \mathrm{ZrMeCl}$ with lithium dialkylamide followed by elimination of methane from the resulting zirconocene(methyl) amide complex, coupled with alkynes to give geometrically pure allylic amines after hydrolysis [33]. They also developed an asymmetric variant of this reaction that proceeded to give allylic amine products with ee's up to $99 \%$ by using chiral ansa-zirconocenes [34]. However, these reactions required a tedious multistep procedure for the preparation of zirconocene-imine complexes. In addition, the use of terminal alkynes produced an inseparable mixture of two regioisomers in some cases [33] or could not give the desired products [34]. Sato et al. reported that a divalent titanium reagent generated by the $\mathrm{Ti}(\mathrm{OiPr})_{4} / 2 \mathrm{iPrMgX}$ system reacted with arylaldimines to provide the corresponding $\left(\eta^{2}\right.$-imine $) \mathrm{Ti}(\mathrm{OiPr})_{2}$ complex that, in turn, reacted with alkynes to give allylic amines after hydrolysis of the resulting azatitanacyclopentenes [35]. In this report, a terminal alkyne showed excellent regioselectivity and much better reactivity than internal alkynes. But only one successful example using a terminal alkyne appeared in this report (1-octyne). Sato's group further applied this reaction for the synthesis of optically active allylic amines with chiral imines and terminal alkynes [36]. However, the imine substrates employed in their reactions were all $N$-alkyl substituted ones $[35,36]$. Until now the scope and limitations for titanium-mediated reductive cross-coupling reactions of imines with terminal alkynes have been far less studied.

Our group has developed a series of reactions using lowvalency titanium reagents [37-39], including selective coupling of 1,3-butadiynes with aldehydes using $\operatorname{Ti}(\mathrm{OiPr})_{4} / 2 n$-BuLi reagent [37] and titanium-mediated formation of cis-[3]cumulenes in the presence of a Lewis acid [38]. Very recently, we reported titanium mediated cross-coupling reactions of imines with ketones or aldehydes by the activation of imines with
$\mathrm{Ti}(\mathrm{OiPr})_{4} / 2 c-\mathrm{C}_{5} \mathrm{H}_{9} \mathrm{MgCl}$ reagent [40-42] leading to 1,2-amino alcohols [39]. These results prompted us to study the crosscoupling of imines with terminal alkynes by using the $\mathrm{Ti}(\mathrm{OiPr})_{4} / 2 c-\mathrm{C}_{5} \mathrm{H}_{9} \mathrm{MgCl}$ reagent. In this paper, we describe the detailed results of these reactions (Scheme 1).

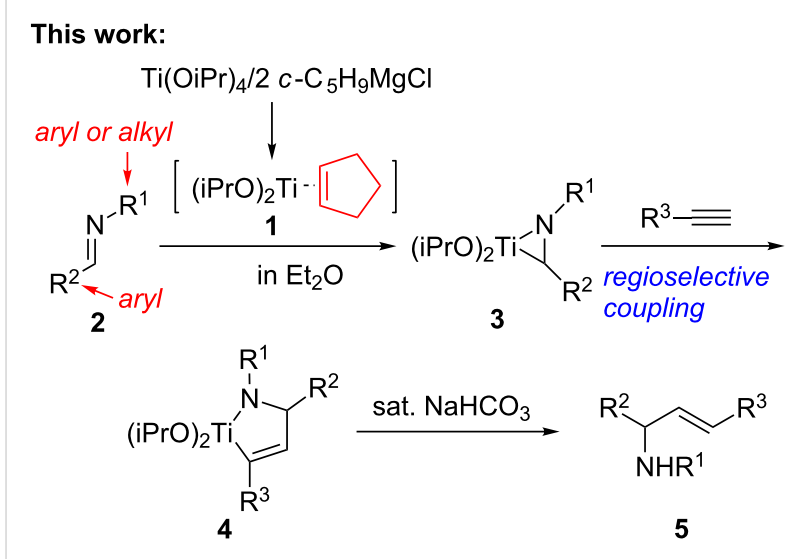

Scheme 1: Titanium-mediated cross-coupling of imines with terminal alkynes.

\section{Results and Discussion}

Synthesis of allylic amines by reductive cross-coupling using $\mathrm{Ti}(\mathrm{OiPr})_{4} / \mathbf{2} c-\mathrm{C}_{5} \mathrm{H}_{9} \mathrm{MgCl}$. First, a typical example for the synthesis of allylic amines by reductive cross-coupling reactions using $\mathrm{Ti}(\mathrm{OiPr})_{4} / 2 c-\mathrm{C}_{5} \mathrm{H}_{9} \mathrm{MgCl}$ reagent was studied by using imine 2a and 1-heptyne as model substrates (Scheme 2). Based on our previous report [39], Ti-imine complex 3a was generated in situ by the reaction of imine 2a with 1.3 equiv of $\mathrm{Ti}(\mathrm{OiPr})_{4} / 2 c-\mathrm{C}_{5} \mathrm{H}_{9} \mathrm{MgCl}$ at $-30{ }^{\circ} \mathrm{C}$. It was found that $\mathrm{Ti}$-imine complex 3a could smoothly couple with 1.5 equiv of 1-heptyne to give allylic amine 5a in 77\% NMR yield after hydrolysis of the resulting azatitanacyclopentene complex $4 \mathbf{a}$ with saturated aqueous $\mathrm{NaHCO}_{3}$ solution. In this reaction, azatitanacyclopentene $\mathbf{4 a}$, rather than its regioisomer $\mathbf{4 a}$ ', was formed preferentially, in which the pentyl group is situated adjacent to titanium (Scheme 3, reaction 1). Accordingly, the allylic amine 5a could be obtained after hydrolysis with excellent regioselectivity. There was no apparent formation of the regioisomer $\mathbf{4 a}$ ' and allylic amine $\mathbf{5 a}$ ' in this reaction, which may be due to the

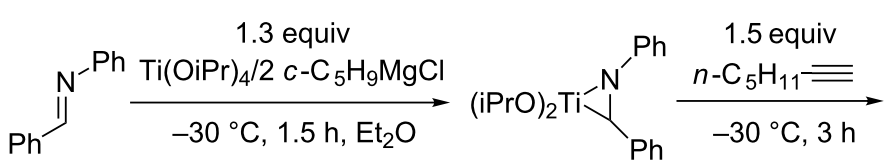

$$
\begin{aligned}
& 2 a \\
& 3 a \\
& (\mathrm{iPrO})_{2} \mathrm{Ti}_{\substack{\mathbf{n} \\
\text { 5a, }}}^{\text {sat. } \mathrm{NaHCO}_{5}}
\end{aligned}
$$




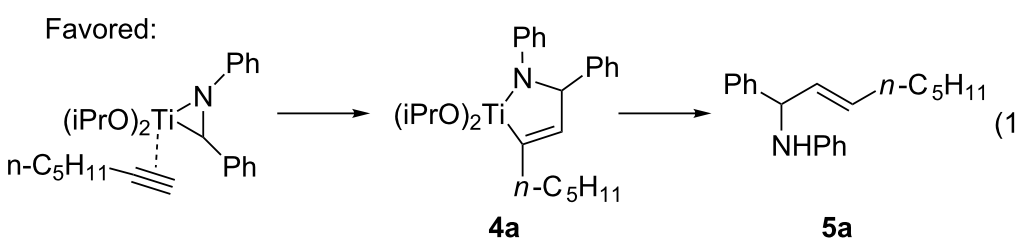

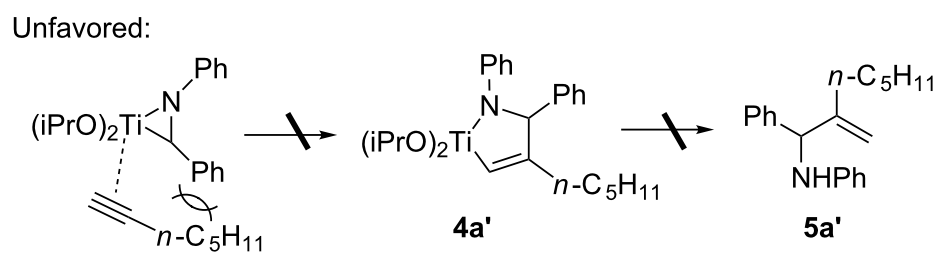

Scheme 3: The regiochemistry of titanium-mediated cross-coupling of imine with terminal alkyne.

strong steric repulsion between the phenyl and pentyl groups during the coupling process (Scheme 3, reaction 2).

Reaction scope of various terminal alkynes and imines. With the optimized reaction conditions in hand, we next investigated the reaction scope by first performing the reaction of imine 2a with various terminal alkynes as shown in Table 1 . When the terminal alkynes with $n$-hexyl or tert-butyl groups were used as coupling partners to react with imine 2a, the corresponding allylic amines $\mathbf{5 b}-\mathbf{c}$ were obtained in $69-88 \%$ yields (Table 1 , entries 2 and 3). The (E)-configuration of allylic amines $\mathbf{5}$ was confirmed by X-ray crystal analysis of $\mathbf{5 c}$ as shown in Figure 1 [43]. Terminal alkynes with chloro- or phenyl-functionalized alkyl chains were both compatible with this coupling reaction, furnishing the corresponding products $\mathbf{5 d}$ and $\mathbf{5 e}$ in $66 \%$ and $68 \%$ yields, respectively (Table 1 , entries 4 and 5 ). Even terminal alkynes with trimethylsilyl or 2-pyridyl functionalities were tolerated well during the reaction to give allylic amines $\mathbf{5 f}$ and $\mathbf{5 g}$ in $80 \%$ and $81 \%$ yields, respectively (Table 1, entries 6 and 7).

A broad range of imine substrates were also examined for this reaction, as shown in Table 2 . When the cross-coupling reactions of $N$-( $p$-bromophenyl)- or $N$-( $p$-methoxyphenyl)-substituted imines $\mathbf{2 b}$ and $\mathbf{2 c}$ were employed with 2-ethynylpyridine under the same conditions, the corresponding allylic amines $\mathbf{5 h}$ and $5 \mathbf{i}$ were obtained in $84 \%$ and $80 \%$ yields, respectively (Table 2, entries 1 and 2). The results indicated that electron-poor or -rich aryl substituents on the nitrogen atom of imines $\mathbf{2}$ had little influence on the yields of products 5 . The reaction of imine 2d, with a bulky $N$-(1-naphthyl) group, with $t$-Bu-substituted alkyne also proceeded well to give allylic amine $\mathbf{5 j}$ in $67 \%$ yield (Table 2 , entry 3$)$. $C$-( $p$-bromophenyl)- or $C$-( $p$-methoxyphenyl)-substituted imines $\mathbf{2 e}$ and $\mathbf{2 f}$ reacted well with a series of terminal alkynes, furnishing $\mathbf{5 k}-\mathbf{5 n}$ in $75-84 \%$ yields

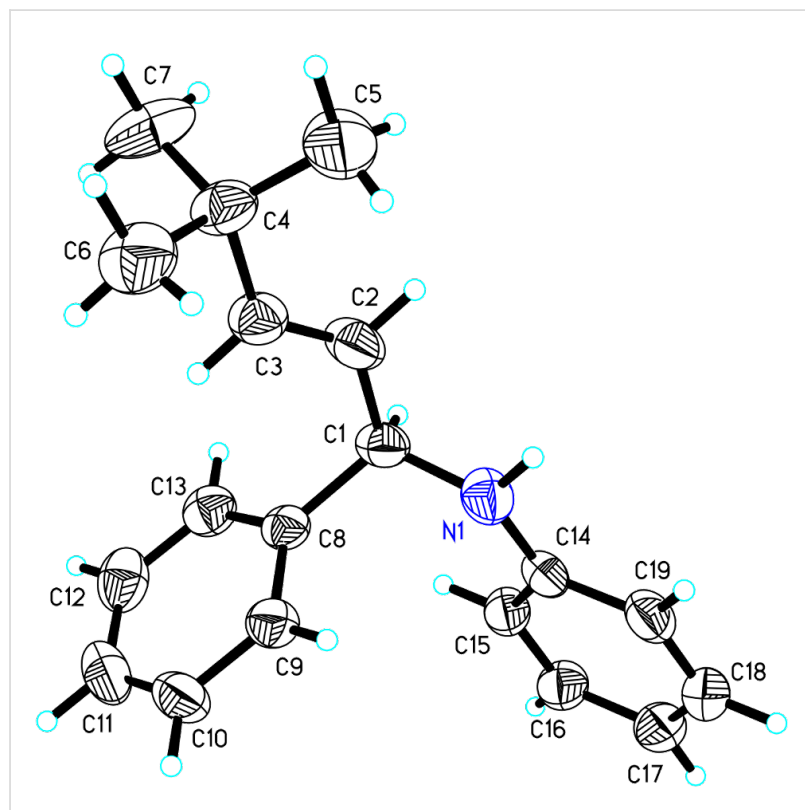

Figure 1: X-ray crystal structure of compound $5 \mathrm{c}$

(Table 2, entries 4-7). The results indicated that the electronic nature of the $C$-aryl ring also had little influence on the product yields. The reaction of $N$-propyl-substituted imine $\mathbf{2 g}$ with 2-ethynylpyridine produced the corresponding allylic amine 50 in $60 \%$ yield (Table 2 , entry 8 ). In contrast to the results obtained by using $\mathrm{Ti}(\mathrm{OiPr})_{4} / 2 \mathrm{iPrMgX}$ reagent [35], the coupling of imine $\mathbf{2 g}$ with 1-octyne could not afford the desired coupling product in our system (Table 2, entry 9). The structure of allylic amines was also determined by X-ray crystal analyses of compounds $\mathbf{5 h}$ and the acylated derivative (7) of $\mathbf{5 l}$ [43].

Titanium-mediated reductive cross-coupling reaction of imines with ethynylcyclopropane. When ethynylcyclopropane was used as the coupling partner of imines $\mathbf{2}$ in the tita- 
Table 1: Synthesis of various allylic amines by titanium-mediated coupling reactions of imine $2 \mathrm{a}$ with different terminal alkynes.

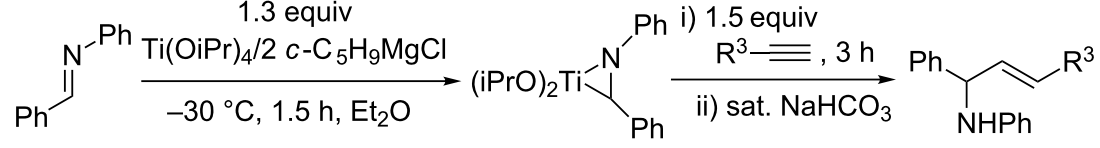

2a

$3 a$

\begin{tabular}{|c|c|c|c|}
\hline entry & terminal alkyne & product & yield $(\%)$ of $2 a^{a}$ \\
\hline 1 & $n-\mathrm{C}_{5} \mathrm{H}_{11}=$ & $5 a$ & 67 \\
\hline 2 & $n-\mathrm{C}_{6} \mathrm{H}_{13}=$ & $5 b$ & 69 \\
\hline 3 & $t-\mathrm{Bu}=$ & $5 c$ & 88 \\
\hline 4 & $\mathrm{Cl}\left(\mathrm{CH}_{2}\right)_{3}=$ & $5 d$ & 66 \\
\hline 5 & $\mathrm{Ph}\left(\mathrm{CH}_{2}\right)_{2}=$ & $5 e$ & 68 \\
\hline 6 & $\mathrm{TMS}=$ & $\begin{array}{r}\mathrm{APh} \\
\mathbf{5 f}\end{array}$ & 80 \\
\hline 7 & $2-\mathrm{Py}=$ & $\begin{array}{r}\mathrm{NHPh} \\
5 \mathrm{~g}\end{array}$ & 81 \\
\hline
\end{tabular}

asolated yields.

nium-mediated reaction, 1,3-amino group migration occurred unexpectedly during the purification of the products by silicagel chromatography (Scheme 4). For example, the reaction of azatitanacyclopropene 3e with 1.5 equiv of ethynylcyclopropane at $-30{ }^{\circ} \mathrm{C}$ for $3 \mathrm{~h}$ afforded, after silica-gel chromatography, the amino-migration product of 1-cyclopropyl allylic

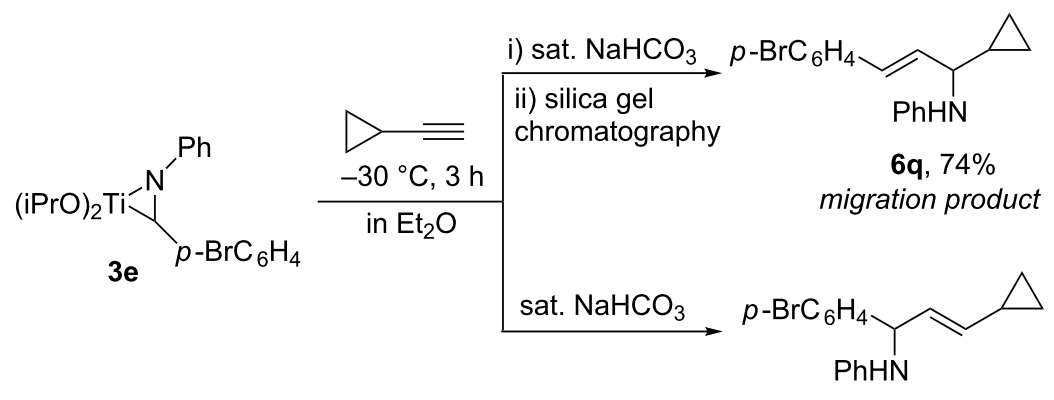

$\mathbf{5 q}, 95 \%$ NMR yield normal product 
Table 2: Synthesis of various allylic amines by titanium-mediated coupling reactions of different imines with terminal alkynes.

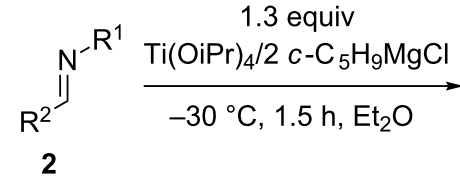

1) 1.5 equiv

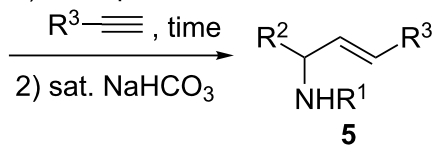

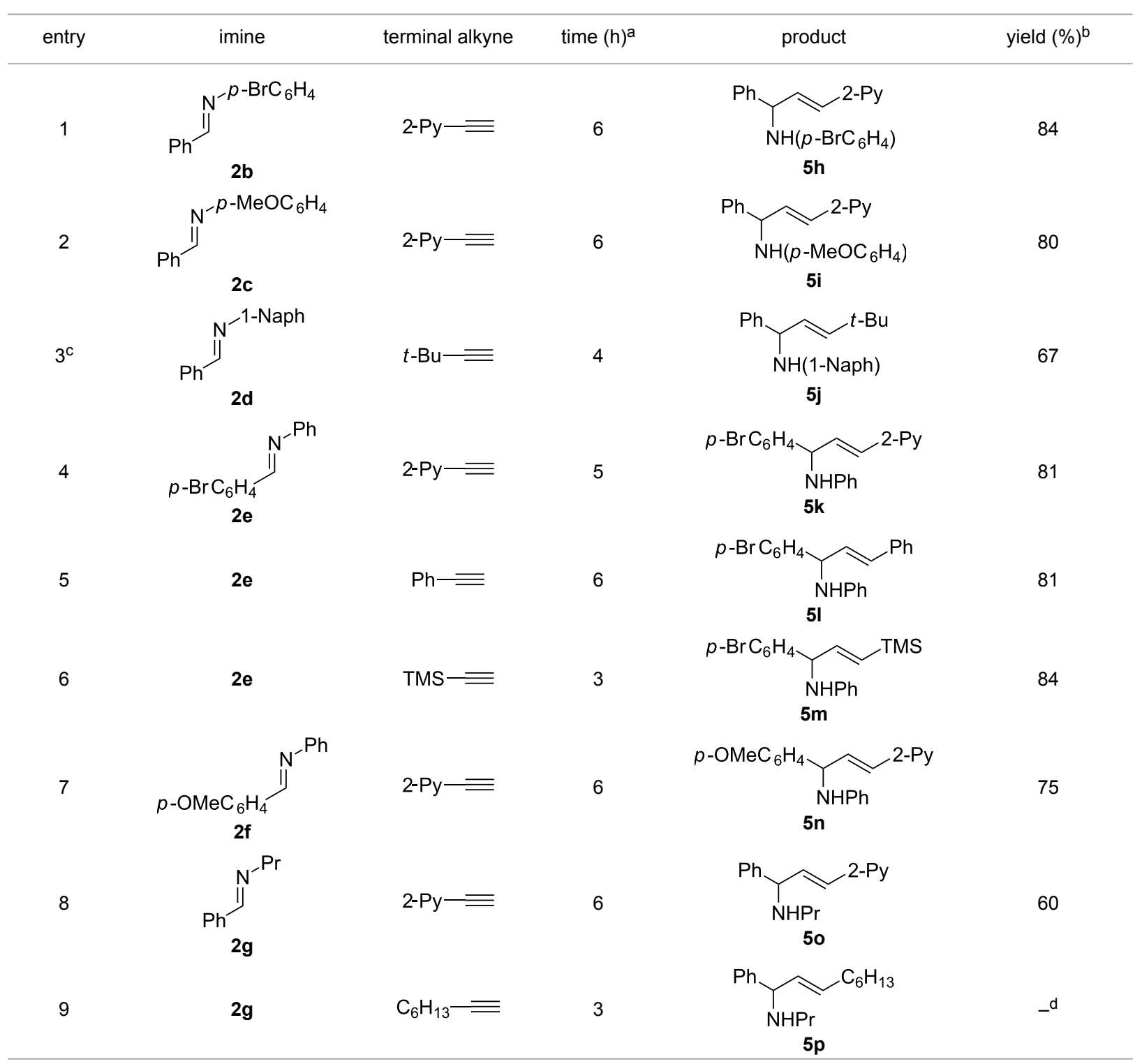

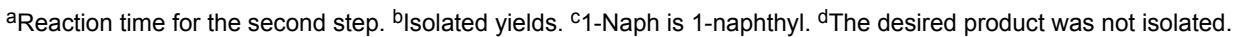

amine $\mathbf{6 q}$ in $74 \%$ yield. The structure of $\mathbf{6 q}$ was confirmed unambiguously by $\mathrm{X}$-ray crystal analysis of its amide derivative 8 ((E)-N-(3-(4-bromophenyl)-1-cyclopropylallyl)-3,5dinitro- $N$-phenylbenzamide) as shown in Figure 2 [43]. Careful analysis of the crude reaction mixture before silica-gel purification revealed that the normal coupling product $\mathbf{5 q}$ was observed in $94 \%$ NMR yield. The result indicated that an isomerization of $\mathbf{5 q}$ to $\mathbf{6 q}$ occurred during the silica-gel isolation process. This isomerization may proceed via the formation of an allyl cationic intermediate promoted by silica gel due to its weak Lewis acidity $[44,45]$.

Iodonolysis of azatitanacyclopentene. Furthermore, we found that iodinated allylic amine 9 could be obtained by iodonolysis of the azatitanacyclopentenes 4 (Scheme 5). For example, on treatment of azatitanacyclopentene $\mathbf{4 g}$ with two equiv of iodine 


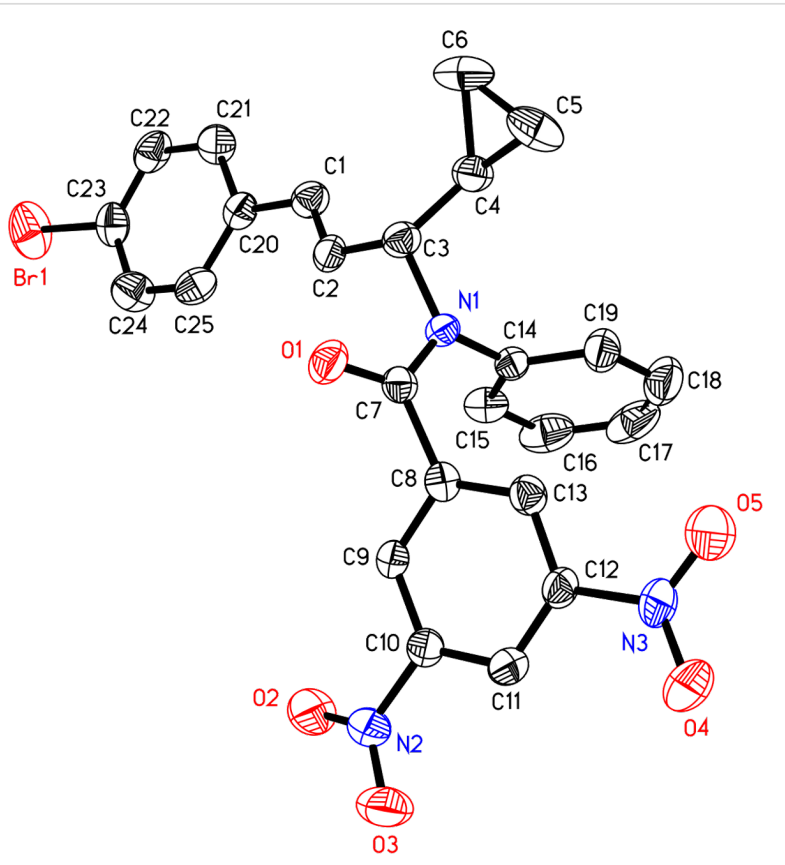

- $\mathrm{BrC}_{6} \mathrm{H}_{4}$

Figure 2: X-ray crystal structure of compound 8.

at $-30{ }^{\circ} \mathrm{C}$ followed by warming to $-10{ }^{\circ} \mathrm{C}$ and stirring for $3 \mathrm{~h}$, iodinated allylic amine 9 could be isolated in $81 \%$ yield. Compound 9 is highly valuable since further functionalization could be explored to synthesize a wide range of organic molecules.

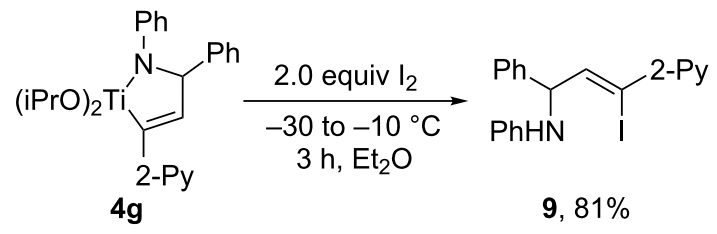

Scheme 5: Synthesis of allylic amine 9 by iodonolysis of azatitanacyclopentene $\mathbf{4 g}$.

\section{Conclusion}

In conclusion, we have developed efficient reductive crosscoupling reactions of imines with terminal alkynes by the activation of imines using $\mathrm{Ti}(\mathrm{OiPr})_{4} / 2 c-\mathrm{C}_{5} \mathrm{H}_{9} \mathrm{MgCl}$ reagent. Various substituted allylic amine derivatives were obtained in good yields and with excellent regioselectivity after hydrolysis or iodonolysis of the resulting azatitanacyclopentenes. Further studies on the synthetic utility of the resulting titanacyclic intermediates and allylic amines are currently in progress.

\section{Acknowledegments}

We thank the National Natural Science Foundation of China (Grant No. 21072208, 21125210, 20821002), Chinese Academy of Science, and the Major State Basic Research Development Program (Grant No. 2011CB808700) for financial support.

\section{Supporting Information}

\section{Supporting Information File 1}

Experimental section and NMR spectra.

[http://www.beilstein-journals.org/bjoc/content/

supplementary/1860-5397-9-69-S1.pdf]

\section{References}

1. Lawrence, S. A. Amines: Synthesis, Properties and Applications; Cambridge University Press: Cambridge, UK, 2004.

2. Cheikh, R. B.; Chaabouni, R.; Laurent, A.; Mison, P.; Nafti, A. Synthesis 1983, 685. doi:10.1055/s-1983-30473

3. Johannsen, M.; Jørgensen, K. A. Chem. Rev. 1998, 98, 1689. doi:10.1021/cr970343o

4. Nag, S.; Batra, S. Tetrahedron 2011, 67, 8959. doi:10.1016/j.tet.2011.07.087

5. Sunderhaus, J. D.; Dockendorff, C.; Martin, S. F. Tetrahedron 2009, 65, 6454. doi:10.1016/j.tet.2009.05.009

6. Pöverlein, C.; Breckle, G.; Lindel, T. Org. Lett. 2006, 8, 819. doi:10.1021/ol0526219

7. Timoshchuk, V. A.; Hogrefe, R. I. Nucleosides, Nucleotides Nucleic Acids 2009, 28, 464. doi:10.1080/15257770903044598

8. Warmus, J. S.; Dilley, G. J.; Meyers, A. I. J. Org. Chem. 1993, 58, 270. doi:10.1021/jo00053a053

9. Monbaliu, J.-C.; Marchand-Brynaert, J. Tetrahedron Lett. 2008, 49, 1839. doi:10.1016/j.tetlet.2008.01.050

10. Lee, H. S.; Kim, H. S.; Kim, J. M.; Kim, J. N. Tetrahedron 2008, 64, 2397. doi:10.1016/j.tet.2008.01.001

11. Scarborough, C. C.; Stahl, S. S. Org. Lett. 2006, 8, 3251. doi:10.1021/ol061057e

12. Hayashi, T.; Yamamoto, A.; Ito, Y.; Nishioka, E.; Miura, H.; Yanagi, K. J. Am. Chem. Soc. 1989, 111, 6301. doi:10.1021/ja00198a048

13. Jumnah, R.; Williams, J. M. J.; Williams, A. C. Tetrahedron Lett. 1993, 34, 6619. doi:10.1016/0040-4039(93)88120-8

14. Burgess, K.; Liu, L. T.; Pal, B. J. Org. Chem. 1993, 58, 4758. doi:10.1021/jo00069a052

15. Bower, J. F.; Jumnah, R.; Williams, A. C.; Williams, J. M. J. J. Chem. Soc., Perkin Trans. 1 1997, 1411. doi:10.1039/A606586D

16. Magnus, P.; Lacour, J.; Coldham, I.; Mugrage, B.; Bauta, W. B. Tetrahedron 1995, 51, 11087. doi:10.1016/0040-4020(95)00696-6

17. Franciotti, M.; Mordini, A.; Taddei, M. Synlett 1992, 137. doi:10.1055/s-1992-21293

18. Luly, J. R.; Dellaria, J. F.; Plattner, J. J.; Soderquist, J. L.; Yi, N. J. Org. Chem. 1987, 52, 1487. doi:10.1021/jo00384a020

19. Kobayashi, S.; Isobe, T.; Ohno, M. Tetrahedron Lett. 1984, 25, 5079 doi:10.1016/S0040-4039(01)91124-4

20. Nishi, T.; Morisawa, Y. Heterocycles 1989, 29, 1835. doi:10.3987/COM-89-5076

21. Sen, S. E.; Roach, S. L. Synthesis 1995, 756. doi:10.1055/s-1995-4012 
22. Overman, L. E.; Zipp, G. G. J. Org. Chem. 1997, 62, 2288. doi:10.1021/jo962129q

23. Guo, S.; Song, F.; Liu, Y. Synlett 2007, 964. doi:10.1055/s-2007-973865

24. Defieber, C.; Ariger, M. A.; Moriel, P.; Carreira, E. M. Angew. Chem., Int. Ed. 2007, 46, 3139. doi:10.1002/anie.200700159

25. Katz, T. J.; Shi, S. J. Org. Chem. 1994, 59, 8297. doi:10.1021/jo00105a063

26. Brucko, M.; Khuong, T.-A. V.; Sharpless, K. B. Angew. Chem., Int. Ed. Engl. 1996, 35, 454. doi:10.1002/anie.199604541

27. Shimizu, Y.; Obora, Y.; Ishii, Y. Org. Lett. 2010, 12, 1372. doi:10.1021/ol100292g

28. Rastogi, N.; Mohan, R.; Panda, D.; Mobin, S. M.; Namboothiri, I. N. N. Org. Biomol. Chem. 2006, 4, 3211. doi:10.1039/b607537a

29. Oi, S.; Moro, M.; Fukuhara, H.; Kawanishi, T.; Inoue, Y. Tetrahedron Lett. 1999, 40, 9259. doi:10.1016/S0040-4039(99)01857-2

30. Wipf, P.; Kendall, C.; Stephenson, C. R. J. J. Am. Chem. Soc. 2003, 125, 761. doi:10.1021/ja028092a

31. Brak, K.; Ellman, J. A. J. Am. Chem. Soc. 2009, 131, 3850. doi:10.1021/ja9002603

32. Li, Y.; Xu, M.-H. Org. Lett. 2012, 14, 2062. doi:10.1021/ol300581n

33. Buchwald, S. L.; Watson, B. T.; Wannamaker, M. W.; Dewan, J. C. J. Am. Chem. Soc. 1989, 111, 4486. doi:10.1021/ja00194a052

34. Grossman, R. B.; Davis, W. M.; Buchwald, S. L. J. Am. Chem. Soc. 1991, 113, 2321. doi:10.1021/ja00006a071

35. Gao, Y.; Yoshida, Y.; Sato, F. Synlett 1997, 1353. doi:10.1055/s-1997-1555

36. Fukuhara, K.; Okamoto, S.; Sato, F. Org. Lett. 2003, 5, 2145. doi:10.1021/ol034599u

37. Chen, J.; Liu, Y. Tetrahedron Lett. 2008, 49, 6655 doi:10.1016/j.tetlet.2008.09.042

38. Chen, J.; Liu, Y. Organometallics 2010, 29, 505 doi:10.1021/om900941y

39. Fan, G.; Liu, Y. Tetrahedron Lett. 2012, 53, 5084. doi:10.1016/j.tetlet.2012.07.020

40. Lecornué, F.; Ollivier, J. Chem. Commun. 2003, 584. doi:10.1039/b211642a

41. McLaughlin, M.; Takahashi, M.; Micalizio, G. C. Angew. Chem., Int. Ed. 2007, 46, 3912. doi:10.1002/anie.200605060

42. Chen, M. Z.; Micalizio, G. C. Org. Lett. 2009, 11, 4982. doi:10.1021/ol902169k

43. CCDC-910581 (5c), 910580 (5h), 910575 (7), 910582 (8) contain the supplementary crystallographic data for this paper. These data can be obtained free of charge from The Cambridge Crystallographic Data Centre via http://www.ccdc.cam.ac.uk/data_request/cif.

44. Shao, L.-X.; Li, Y.-X.; Shi, M. Chem.-Eur. J. 2007, 13, 862. doi:10.1002/chem.200600722

45. Eşsiz, S.; Şengül, M. E.; Şahin, E.; Daştan, A. Turk. J. Chem. 2011, 35, 587. doi:10.3906/kim-1101-991

\section{License and Terms}

This is an Open Access article under the terms of the Creative Commons Attribution License

(http://creativecommons.org/licenses/by/2.0), which permits unrestricted use, distribution, and reproduction in any medium, provided the original work is properly cited.

The license is subject to the Beilstein Journal of Organic Chemistry terms and conditions:

(http://www.beilstein-journals.org/bjoc)

The definitive version of this article is the electronic one which can be found at: doi:10.3762/bjoc.9.69 